\title{
Unequal Gain of Equal Resources across Racial Groups
}

\author{
Shervin Assari ${ }^{1,2,3^{*}}$
}

\begin{abstract}
The health effects of economic resources (eg, education, employment, and living place) and psychological assets (eg, self-efficacy, perceived control over life, anger control, and emotions) are well-known. This article summarizes the results of a growing body of evidence documenting Blacks' diminished return, defined as a systematically smaller health gain from economic resources and psychological assets for Blacks in comparison to Whites. Due to structural barriers that Blacks face in their daily lives, the very same resources and assets generate smaller health gain for Blacks compared to Whites. Even in the presence of equal access to resources and assets, such unequal health gain constantly generates a racial health gap between Blacks and Whites in the United States. In this paper, a number of public policies are recommended based on these findings. First and foremost, public policies should not merely focus on equalizing access to resources and assets, but also reduce the societal and structural barriers that hinder Blacks. Policy solutions should aim to reduce various manifestations of structural racism including but not limited to differential pay, residential segregation, lower quality of education, and crime in Black and urban communities. As income was not found to follow the same pattern demonstrated for other resources and assets (ie, income generated similar decline in risk of mortality for Whites and Blacks), policies that enforce equal income and increase minimum wage for marginalized populations are essential. Improving quality of education of youth and employability of young adults will enable Blacks to compete for high paying jobs. Policies that reduce racism and discrimination in the labor market are also needed. Without such policies, it will be very difficult, if not impossible, to eliminate the sustained racial health gap in the United States.

Keywords: Racial Health Disparities, Structural Barriers, Racism, Health Policy, Public Policy

Copyright: @ 2018 The Author(s); Published by Kerman University of Medical Sciences. This is an open-access article distributed under the terms of the Creative Commons Attribution License (http://creativecommons.org/licenses/ by/4.0), which permits unrestricted use, distribution, and reproduction in any medium, provided the original work is properly cited.

Citation: Assari S. Unequal gain of equal resources across racial groups. Int J Health Policy Manag. 2018;7(1):1-9. doi:10.15171/ijhpm.2017.90
\end{abstract}

Article History:

Received: 5 December 2016 Accepted: 24 July 2017 ePublished: 5 August 2017

View Video Summary 00
$D$

*Correspondence to:

Shervin Assari

Email: assari@umich.edu

\section{Economic Resources and Psychological Assets Impact} Health

The protective health effects of economic resources (eg, education and employment) ${ }^{1}$ and psychological assets (eg, self-efficacy, perceived control over life, anger control, and emotions $)^{2-6}$ are well-known. Mirowsky and Ross have described the health effects of socio-economic status (SES) as "enduring, consistent, and growing." Psychological assets such as emotion regulation, positive emotions, self-efficacy, and sense of control over life are also essential for maintaining health. ${ }^{8-10}$ These resources and assets increase access to material and human resources which collectively enable individuals to avoid risks and minimize their negative consequences as they occur. ${ }^{11,12}$ The aim of this paper is to review and discuss a growing body of literature which documents systematically smaller health effects of SES resources and psychosocial assets for Blacks compared to Whites in the United States. That is minority status bounds the potential gains that follow SES resources and psychological assets, also known as Blacks' diminished return. ${ }^{13}$

State-of-the-art longitudinal studies, such as the Health and Retirement Study (HRS), ${ }^{14}$ the Panel Study of Income Dynamics, ${ }^{15}$ the British Whitehall Study, ${ }^{16}$ the British Cohort
Study (BCS), ${ }^{17}$ the French GAZEL cohort, ${ }^{18}$ the Survey of Health, Aging and Retirement in Europe (SHARE), ${ }^{19}$ and Americans' Changing Lives (ACL) study ${ }^{20}$ have all documented strong protective effects of educational attainment, employment, and income against risk of morbidity ${ }^{21}$ and mortality. ${ }^{22}$ Longitudinal studies have also shown that high levels of psychological assets such as mastery, self-efficacy, perceived control over life, emotion regulation, positive emotions, and anger control are also protective against morbidity and mortality. ${ }^{23-28}$ In fact, there is some evidence suggesting that these psychological assets are one of the mechanisms by which high SES protects health..$^{29,30}$ For instance, mastery is shown to mediate the effects of both earlier- and later-life economic hardships on elders' physical and mental health. High mastery also buffers the impact of economic hardship on health outcomes of older aults. ${ }^{31}$

\section{Unequal Gain From Equal Resources and Assets}

In nearly 20 papers (see Table 1), my colleagues and I have found that in the United States, economic resources and psychological assets systemically result in a smaller health gain for Blacks compared to Whites. These findings hold for a wide range of SES resources (eg, education, ${ }^{32}$ employment, ${ }^{33}$

${ }^{1}$ Center for Research on Ethnicity, Culture and Health (CRECH), School of Public Health, University of Michigan, Ann Arbor, MI, USA. ${ }^{2}$ Department of Psychiatry, University of Michigan, Ann Arbor, MI, USA. ${ }^{3}$ Institute for Healthcare Policy and Innovation (IHPI), University of Michigan, Ann Arbor, MI, USA. 
Table 1. Our Findings on Weaker Effects of Psychosocial Factors on Health of Blacks Than Whites

\begin{tabular}{|c|c|c|c|c|c|c|}
\hline Author & Data Set & Longitudinal & Follow Up & Gender & Predictor & Outcome \\
\hline Assari and Lankarani ${ }^{32}$ & $\mathrm{ACL}$ & + & 25 Years & Men & Education & All-cause mortality \\
\hline Assari ${ }^{33}$ & $\mathrm{ACL}$ & + & 25 Years & Both & Employment & All-cause mortality \\
\hline Assari $^{34}$ & $\mathrm{ACL}$ & + & 25 Years & Both & Neighborhood safety & All-cause mortality \\
\hline Assari and Lankarani ${ }^{35}$ & $\mathrm{ACL}$ & + & 25 Years & Both & SRH & All-cause mortality \\
\hline Assari et $\mathrm{al}^{36}$ & $\mathrm{ACL}$ & + & 25 Years & Both & Depression & Chronic disease \\
\hline Assari et $\mathrm{al}^{37}$ & $\mathrm{ACL}$ & + & 25 Years & Both & Depression & All-cause mortality \\
\hline Assari and Lankarani ${ }^{38}$ & $\mathrm{ACL}$ & + & 25 Years & Both & Depression & Chronic disease \\
\hline Assari ${ }^{39}$ & $\mathrm{ACL}$ & + & 25 Years & Both & Anger and hostility & Cause-specific mortality \\
\hline Assari et $a^{40}$ & $\mathrm{ACL}$ & + & 25 Years & Both & Restless sleep & Chronic disease \\
\hline Assari ${ }^{41}$ & $\mathrm{ACL}$ & + & 25 Years & Both & Self-efficacy & All-cause mortality \\
\hline Assari ${ }^{42}$ & RAHS & + & 3 Years & Both & Sense of control & All-cause mortality \\
\hline Assari and Burgard ${ }^{43}$ & $\mathrm{ACL}$ & + & 25 Years & Both & Depression & Cause-specific mortality \\
\hline Assari et al ${ }^{44}$ & HRS & + & 6 Years & Men & Education & Sleep, BMI, physical activity \\
\hline Assari ${ }^{45}$ & $\mathrm{ACL}$ & + & 25 Years & Men & Education & Depression \\
\hline Assari ${ }^{46}$ & NSAL & - & - & Men & Education & Suicidal Ideation \\
\hline Assari ${ }^{47}$ & RAHS & - & - & Both & Life purpose & $\mathrm{BMI}$ \\
\hline Assari and Lankarani ${ }^{48}$ & RAHS & - & - & Both & Education & Alcohol Use \\
\hline Assari and Lankarani ${ }^{49}$ & NSAL & - & - & Men & Stress & Depression \\
\hline Assari ${ }^{50}$ & NSAL & - & - & Men & Depression & Obesity \\
\hline Assari et al ${ }^{51}$ & FFWS & + & 15 Years & Both & Family SES & Obesity \\
\hline Assari $^{52}$ & NSAL & - & - & Men & Income & Depression \\
\hline Assari $i^{53}$ & FFWS & + & 15 Years & Both & Family SES & SRH \\
\hline Assari and Lankarani ${ }^{54}$ & NSAL & - & - & Both & Obesity & Intention to reduce weight \\
\hline
\end{tabular}

Abbreviations: SRH, Self-rated Health; BMI, body mass index; ACL, Americans' Changing Lives; SES, socio-economic status; HRS, Health and Retirement Study; RAHS, Religion, Aging, and Health Survey; FFWS, Fragile Families and Child Wellbeing Study; NSAL, National Survey of American Life.

and neighborhood safety ${ }^{34}$ ) as well as psychological assets (eg, emotions, ${ }^{36-38}$ anger management, ${ }^{39}$ sleep quality, ${ }^{40}$ self-efficacy, ${ }^{41}$ perceived control over life, ${ }^{39}$ and self-rated health ${ }^{35}$ ) on health. These differential effects are found for several physical health outcomes such as incident chronic disease, ${ }^{36,38,40}$ all-cause mortality, ${ }^{37,41,42}$ and cause-specific mortality. ${ }^{43}$ These findings are not specific to a particular risk factor or outcome. ${ }^{47-50}$

My team and I have generated these findings using the following national longitudinal studies: (1) the ACL study, 1986-2011, a 25-year cohort of 3600+ adults, (2) the Midlife in the United States (MIDUS) study, 1995-2004, a 10-year cohort of 7100+ adults, and (3) the Religion, Aging, and Health Survey (RAHS), 2001-2004, a 3-year cohort of 1500 older adults, and Health and Retirement Study (HRS), 1992-current, a 25-year cohort of $37000+$ older adults. As all these longitudinal cohort studies have recruited a national sample, the results are generalizable to the US population. The findings are robust and hold independent of setting, cohort, age group, psychosocial determinants, and health outcome. Other researchers have also reported similar findings ${ }^{55-81}$ (see Table 2).

To give a few examples of our findings, high education credentials failed to reduce the risk of physical inactivity, ${ }^{44}$ obesity, ${ }^{44}$ depressive symptoms, ${ }^{45}$ and suicidal ideation ${ }^{46}$ among Blacks. In a paper, among Black men, high educational attainment was predictive of an increase in depressive symptoms over time. ${ }^{45}$ Among Black women, high educational attainment was associated with high suicidal ideation. ${ }^{46}$

Similar Findings in the Literature

Findings mentioned above (Table 1) have been supported by other researchers (Table 2). In a recent paper published in Social Sciences and Medicine, Malat, Mayorga-Gallob, and Williams discussed the issue. ${ }^{82}$ They attributed the larger effects of social and psychological factors in Whites to their Whiteness (social privilege). ${ }^{82}$ Williams, Kessler, Neighbors, and others have emphasized the need for systematically testing potential interactions between race and SES on health. ${ }^{83,84}$ Mehta has shown how behavioral risk factors interact with sociodemographic characteristics on risk of mortality. ${ }^{85}$ Kaufman, however, has discussed that due to potential biases such as residual confounding, it is always difficult to decompose the health effects of race from SES. ${ }^{86}$ Farmer and Ferraro documented largest racial gap in selfrated health at the higher levels of SES, supporting Blacks' "diminishing returns." Their paper showed that as education levels increases, Blacks do not gain as much self-rated health as their White counterparts. ${ }^{13}$ Similarly, Fuller-Rowell and colleagues found a weaker health effect of educational attainment for Blacks than for Whites. ${ }^{59}$ Brown et al found that eliminating gap in childhood SES, adult social and economic resources, and health behaviors do not fully eliminate racialethnic disparities in health trajectories, suggesting that the mechanism generating health disparities is more than differential exposures to resources. ${ }^{87}$

Under the same family income, Black households have a lower rate of wealth production, which has direct and indirect health implications. Compared to Whites, Black households more commonly rely on several wage earners to contribute to the total household income. ${ }^{88}$ Middle class Blacks are more likely than their White counterparts to be recent and tenuous in that class status. ${ }^{89}$ College-educated Blacks are several times more likely than their White peers to be unemployed. ${ }^{90}$ The 
Table 2. Findings by Other Researchers on the Black-White Differences in the Effects of Psychosocial Factors on Health

\begin{tabular}{|c|c|c|c|c|c|c|}
\hline Author & Data set & Longitudinal & Follow Up & Gender & Predictor & Outcome \\
\hline Kessler et $\mathrm{al}^{55}$ & MIDUS & - & - & Both & Discrimination & Mental health \\
\hline Geronimus et $\mathrm{al}^{56}$ & - & - & - & Both & Poverty and urban stressors & Telomere length \\
\hline Ferraro and Kelley-Moore ${ }^{57}$ & NHANES & + & 20 Years & Both & SRH & All-cause mortality \\
\hline Zajacova and Dowd ${ }^{58}$ & NHANES & - & - & Both & SRH & All-cause mortality \\
\hline Fuller-Rowell et al ${ }^{59}$ & - & - & - & Both & Discrimination & Diurnal cortisol rhythm \\
\hline Fuller-Rowell et al ${ }^{60}$ & - & - & - & Both & Education & Inflammation \\
\hline Miller and Korenma ${ }^{61}$ & NLSY & - & - & Both & Poverty & $\begin{array}{l}\text { Stunting (low height-for-age) and } \\
\text { wasting (low weight-for-height) }\end{array}$ \\
\hline Allen et al $^{62}$ & HANDLS & - & - & Both & Urban food-insecurity & Diet quality \\
\hline Barnes et $\mathrm{al}^{63}$ & CHAP & + & 5 Years & Both & Discrimination & Mortality \\
\hline Tang et $a^{64}$ & & & & & APOE-3 & Alzheimer disease \\
\hline Rajan et $\mathrm{l}^{65}$ & CNDS & + & 7 Years & Both & Depression & Disability \\
\hline Everson-Rose et al ${ }^{66}$ & CHAP & + & 7 Years & Both & Neighborhood SES & Hostility \\
\hline Koebnick et al ${ }^{67}$ & - & + & - & Both & Obesity & Asthma \\
\hline Kubzansky et al ${ }^{68}$ & MSSA & - & - & Both & SES & Distress \\
\hline Gavin et $\mathrm{al}^{69}$ & CPES & - & - & Female & Obesity & Depression \\
\hline Calle et $\mathrm{al}^{70}$ & CPS & + & 14 Years & Both & Obesity & All-cause mortality \\
\hline Stevens et $\mathrm{al}^{71}$ & CPS & + & 14 Years & Both & Obesity & All-cause mortality \\
\hline Hogue et $\mathrm{al}^{72}$ & NIMS & + & 28 Days & Both & Birth weight & Infant mortality \\
\hline Cené et $\mathrm{al}^{73}$ & - & - & - & Both & Subjective social status & Physical and mental health \\
\hline Ebong et $\mathrm{al}^{74}$ & - & - & - & Both & Mood & Insomnia \\
\hline Shaw and Krause $\mathrm{e}^{75}$ & $\mathrm{ACL}$ & - & - & Both & Education & Feelings of control \\
\hline Plotnick et al ${ }^{76}$ & NLSU & + & 5 Years & Female & Child support & Teenage premarital childbearing \\
\hline Gardener et $\mathrm{al}^{77}$ & NMS & & - & Both & Mediterranean diet & Carotid atherosclerosis \\
\hline Katzmarzyk et $\mathrm{al}^{78}$ & PCLS & + & 8 Years & Both & BMI & Mortality \\
\hline Anderson et $\mathrm{al}^{79}$ & - & - & - & Both & Pain & Medication adherence \\
\hline Maynard et al ${ }^{80}$ & - & - & - & Both & Income & Obesity and myocardial infarction \\
\hline Samuel et al ${ }^{81}$ & - & - & - & Both & $\begin{array}{l}\text { Community problems and } \\
\text { resources }\end{array}$ & $\begin{array}{l}\text { Systolic and diastolic blood } \\
\text { pressure }\end{array}$ \\
\hline
\end{tabular}

Abbreviations: SRH, Self-rated Health; BMI, body mass index; ACL, Americans' Changing Lives; SES, socio-economic status; CPS, Cancer Prevention Study II; CHAP, Chicago Health and Aging Project; CNDS, Chicago Neighborhood and Disability Study; CPES, Comprehensive Psychiatric Epidemiology Surveys; MSSA, MacArthur Studies of Successful Aging; NHANES, National Health and Nutrition Examination Survey; NIMS, National Infant Mortality Surveillance; NLSY, National Longitudinal Survey of Youth; NMS, Northern Manhattan Study; PCLS, Pennington Center Longitudinal Study.

purchasing power at a given level of income varies by race, as Blacks are paying higher prices than Whites for a broad range of goods and services, including food and housing. ${ }^{91}$ If employed, Blacks are more likely than Whites to be exposed to occupational hazards and carcinogens, even after adjusting for job experience and education. ${ }^{83}$

Blacks also have higher levels of goal-striving stress, John Henryism $(\mathrm{JH})$, and other types of effortful coping strategies for upward social mobility. These coping strategies, however, come with psychological and physiological costs. ${ }^{92-94}$ Although most of the literature on health damage due to $\mathrm{JH}$ is limited to mental distress and depression, ${ }^{95}$ health disadvantage associated with $\mathrm{JH}$ may go beyond a psychological cost, ${ }^{96,97}$ particularly when high JH co-exists with low resources (SES) and social support. ${ }^{92} \mathrm{JH}$ is reported to be associated with high cardiovascular risk. ${ }^{98} \mathrm{JH}$ may be a resource or a health hazard, ${ }^{98}$ depending on the outcome and availability of other risks and resources. ${ }^{95}$

\section{What Do These Findings Mean?}

According to our findings, the protective effects of psychosocial resources (eg, education, employment, and neighborhood) on health should not be considered equal between Whites and Blacks. ${ }^{32,44,45}$ The impact of psychosocial resources on health outcomes are conditional to factors such as poverty, residential segregation, and structural racism. ${ }^{99-102}$ The weaker effects of high SES for Blacks could be due to differential SES at early childhood in White and Black families. As Warner and Hayward, ${ }^{103}$ and Colen $^{104}$ have argued, unequal SES at childhood may be a reason for the non-equivalence of SES effects between Whites and Blacks during adulthood. Thus, public and health policies should go beyond equalizing access to resources and additionally eliminate structural barriers that Blacks face.

According to the Blacks' diminishing returns, education and employment have weaker effects on health of Blacks in comparison to Whites. ${ }^{105}$ Smaller health gains from education and employment among Blacks may be in part due to the racial wage gap in the United States labor market. ${ }^{106-108}$ Blacks and Whites enter different types of occupations. ${ }^{109}$ When employed, Blacks are paid considerably less than Whites, particularly in higher levels of education. ${ }^{110}$ In 2006, Black men with a master's degree earned \$27000 less than White men with the same credentials. ${ }^{111}$ As Marmot has argued, although the availability of socio-economic resources is also important, what social groups can do with those resources is even more important. ${ }^{110}$

Increasing access to education and employment alone is not enough to eliminate racial health disparities in the United States. What is also needed is parity in wages and quality 
of education. Interestingly, such Black-White differences do not hold for health gains associated with income. ${ }^{32}$ That is income similarly reduces risk of mortality for Blacks and Whites. This finding emphasizes the importance of increasing the minimum wage and reducing the racial wage gap in the United States. Hiring and housing practices (ie, zip code discrimination; discrimination by banks in the maintenance of homes in majority Black neighborhoods) that constrain the ability of Blacks to equitably compete with Whites should also be rigorously addressed. ${ }^{111}$ Without improving the quality of education in majority Black schools that are limited in educational resources, ${ }^{112}$ and without increasing the minimum wage for Blacks, education and employment will continue to provide diminished health protection for Blacks.

\section{Racism Is a Multilevel System and Needs Multilevel Policy} Solutions

In their 2011 Du Bois Rev, Gee and Ford argued that the main origin of health disparities across social groups is structural, rather than individual, phenomena. They argued that various aspects of structural racism such as social segregation, immigration policy, and intergenerational effects are in charge of maintaining health disparities. As a result, policies should attack various dimensions of structural racism as fundamental causes of health disparities. ${ }^{113}$

Barbara Reskin has helped us better understand the types of policies that are needed to undo racism in the United States. Drawing on a systems perspective, she has defined racism in the United States as a discrimination system that constantly generates racial disparities across multiple domains (eg, residential location, schooling, employment, health, housing, credit, and justice). Policy solutions should consider that domains are reciprocally related and comprise an integrated system. She argues that appropriate response should include implementing interventions to operate simultaneously across subsystems, and directly challenging the processes through which the emergent discrimination strengthens the subsystems. ${ }^{114}$

Williams and Mohammed defined racism as a multi-level system embedded in American society. ${ }^{101}$ Authors explained that racism adversely affects the health of non-dominant racial populations in three levels. First, through a number of policies and procedures, institutional racism has systematically reduced access of minorities to housing, neighborhood and educational quality, employment opportunities, and other desirable resources in society. Second, cultural racism operates through stereotype threat and internalized racism. Both at the societal and individual level, it generates culture and a policy environment that is hostile to egalitarian policies and triggers negative stereotypes and discrimination that are detrimental to health and foster health-damaging psychological and behavioral responses. Third, racial discrimination functions as a unique psychosocial stressor in the interpersonal and personal levels. ${ }^{101}$

As racial disparities are generated by a multi-level system, the responses should also target a wide range of policies that operate in those systems. First, in response to the institutional racism, policies are needed that improve neighborhood and educational quality and enhance access to additional income, employment opportunities and other desirable resources.
Second, to undo disparities due to cultural racism, policies and interventions are needed at the societal and individual levels. Finally, policies are needed to maximize the healthenhancing capacities of medical care, address the social factors that initiate and sustain risk behaviors and empower individuals and communities to take control of their lives and health. ${ }^{115}$

Geronimus and colleagues suggest that health disparities are due to structurally-rooted biopsychosocial processes. They have coined the term Jedi Public Health (JPH) "which focuses on changing features of settings in everyday life, rather than individuals, to promote population health equity, a high priority, yet, elusive national public health objective."116 They called both for an expansion and a re-orienting efforts to eliminate population health inequities. Based on their framework, there is a need for policies and interventions that remove and replace discrediting cues in everyday settings. Such policies will disrupt the repeated physiological stress process activation that fuels population health inequities. ${ }^{116}$

Initial advantage (eg, economic resources, health status, and cognitive ability) leads to cumulative differences that widen pre-existing gaps. ${ }^{117}$ For example, according to the cumulative advantage theory in the area of child development, initial advantage leads to further cumulative advantage and initial disadvantage being accentuated over time. ${ }^{118}$

\section{Widening the Gap Has Happened Before and May Happen Again}

In fact, the United States may experience a widening of racial health disparities if disproportionate gains of majority and minority as well as high and low SES groups are continued. Williams and Collins have provided a historical review regarding how the gap may increase for mortality. ${ }^{83}$ Authors showed that a decline in Black economic well-being and an increase in Black-White inequality resulted in worsening Black health across a number of health status indicators. For instance, the Black-White gap in life expectancy widened, between 1980 and 1991, from 6.9 years to 8.3 years for males and from 5.6 years to 5.8 years for females. ${ }^{83}$ As explained by Williams and Collins, ${ }^{83}$ for every year between 1985 and 1989, the life expectancy for both African American men and women declined from the 1984 level. ${ }^{119}$ A slower rate of decline among Blacks than Whites for heart disease was the chief contributor to the widening racial gap in life expectancy in the past decades. ${ }^{83,120}$ Williams and Collins further explain that the age-adjusted Blacks to Whites death ratio was greater in 1991 than in 1980, and the annual number of excess deaths in Blacks compared to Whites showed a 6000 increase, from 60000 to 66000 , from 1980 to 1991 . During this period, the reason behind the widening gap was that the overall age-adjusted death rate decreased more rapidly for Whites than for Blacks. ${ }^{83}$ Freeman showed that, in the same period (1960-1980), a steady decline could be observed in national mortality; however, there was zero gain in life expectancy for Blacks in Harlem over this 20 -year period. ${ }^{83}$

The racial gap in health worsens when the economic gap widens. In 1978, Black households received 58\% of what Whites earned, but Blacks made far less compared to Whites during the 1980s. In parallel to the widening of economic gap, racial disparities in health also widened across a wide 
range of health indicators. ${ }^{121}$ For example, from 1984 to 1989 , a consistent increase was observed in the life expectancy of Whites; however, the life expectancy of Blacks declined at this time. ${ }^{83}$

Other researchers have also described the failure of narrowing mortality disparities due to SES. ${ }^{122-124}$ Duleep showed that socioeconomic differences in mortality in the United States did not decline from 1960 to 1970 for men aged 25-65 years old. ${ }^{124}$ Feldman and colleagues found that the protective effect of education on mortality increased substantially between 1960 and 1984 for White men, but not for Black men. ${ }^{123}$ Pappas and colleagues compared mortality data from 1960 to 1986 and found evidence for an increase in SES disparity over that period. ${ }^{125}$ Wagener and Shatzkin ${ }^{126}$ showed that from 1969 to 1989 , breast cancer mortality declined for women in high SES counties in the United States but increased for women in low SES counties. Finally, the gap in infant mortality rates for White and Black babies widened for each sex between 1980 and 1991. At the same time period, rates of both preterm delivery and low birth weight remained stable for White women, but have been increasing among Blacks. ${ }^{127}$ Castro showed a differential widening in the rates of sexually transmitted diseases between Blacks and Whites. ${ }^{128}$ These studies show that: (1) the historical widening of a racial gap has occurred and may occur again, (2) the widening of a racial gap may occur when the health of Whites and high SES groups improves with a faster pace than other groups, (3) the racial gap in health follows an increase in economic disparities, and (4) the possibilities of widening the racial gap are not specific to a single health outcome, as they spill over to multiple health domains. ${ }^{83}$

\section{Recommended Policy Solutions}

Given the existing unequal gain of equal resources, policies that merely focus on the equal distribution of resources and ignore the differential distribution of barriers across groups may have the unintended effect of exacerbating the existing racial health inequities rather than reducing them. Despite their good will, employment and educational initiatives that do not account for deeply rooted structural inequalities that Blacks face may do little to reduce the racial health disparity gap in the United States. Universal investments that equalize access and ignore the structural barriers which hold Blacks behind from translating those resources to gains have the risk of widening the racial health gap, given the higher readiness of Whites to absorb such resources.

Policies and programs should be tailored to the specific needs of Blacks. Policies should specifically address multilevel structural barriers and constraints that limit Blacks' ability to translate their available social resources and psychological assets into health gains. Socioeconomic barriers that are prevalent in Black communities should be considered, especially if the highest effects are expected for any new social and public policies that aim to reduce racial health disparities.

Racial segregation, for instance, operates as a structural and contextual barrier for many Blacks today. Discriminatory mortgage and loan policies which include higher bars and thresholds that Blacks should meet to qualify for loans in addition to higher interest rates and higher down payment for Blacks are still in practice, ${ }^{129}$ despite all the existing antidiscriminatory laws. Affirmative action ${ }^{130}$ policies may need to be reevaluated considering these findings on the diminished gains of equal resources among Blacks. Authors acknowledge that it is much easier to point out a problem. As a society, we all need to challenge the political system to approve appropriate alleviative policies. ${ }^{131}$

\section{Our Work Supports Previous Arguments}

Our findings lend empirical support for the argument by Ceci and Papierno that the "Haves" always gain more than the "Have-Nots" from universal interventions. They explained that the disparities in gain which cumulates over time is a potential source of widening the disparities. ${ }^{132}$ They mentioned that several interventions, across different domains, have the unintended effect of widening pre-existing gaps between disadvantaged and advantaged populations, if such interventions are made available to all populations, regardless of their social and economic disadvantage status. Policy-makers should be aware of the gap-widening potential of such universal interventions and policies. Given the political and economic climate, many of the interventions will elevate the socially and economically advantaged populations to a greater degree than the disadvantaged group - certain policies may inadvertently widen the existing gap." ${ }^{32}$

In 2016, Williams and Purdie-Vaughns outlined the challenge that some of the interventions that have the potential to improve health at the population level can widen social inequalities in health. ${ }^{133}$ They recommended that policymakers should consider the significance of race/ethnicity in designing and developing good policies to inequalities and disparities. They also emphasized the existing need to develop a scientific research agenda to identify the distinction between the policies that reduce and those who widen the existing racial/ethnic health disparities. ${ }^{133}$

In 2013, Lorenc and colleagues reviewed interventions generating inequalities (IGIs), ${ }^{134}$ defined as effective public health interventions that increase inequalities by disproportionately benefiting less disadvantaged groups. Still, less is known about which types of interventions are likely to widen the gap, and which can reduce or eliminate the inequalities. Media campaigns; and workplace smoking bans are IGIs, however, structural workplace interventions; provision of resources; and fiscal interventions, such as tobacco pricing may reduce the gap. ${ }^{134}$

\section{Need for Further Research}

Although our review clearly shows that with income being the exception, economic resources and psychological assets better protect Whites than Blacks. There is a need for research in this area that would help us better understand these differential effects. ${ }^{135}$ For instance, it is unclear whether upward social mobility has more social costs for Blacks than Whites. ${ }^{136}$ Despite Blacks have smaller health gains than Whites from most "psychological assets," this is not the case with religious involvement and social support. Regarding religious involvement and spirituality, Blacks both report higher levels and experience greater health benefits from each unit of them. Using national data, Hummer and colleagues have shown, that high levels of religious attendance is associated with a 7 
year gain in life expectancy for Whites but a 13 year gain for Blacks. ${ }^{137,138}$ Keyes shows that Blacks, despite all of their stress and adversity have higher levels of "flourishing" than Whites (ie, high levels of psychological well-being and low rates of mental illness). ${ }^{139,140}$ In 1978, Kessler showed that although Blacks and low SES persons report higher levels of stressful life events than their White and high SES counterparts, a given stressor may have more negative effects on the health of Whites and high SES persons than on their more socially disadvantaged peers. ${ }^{141}$ Krause, ${ }^{142-144}$ Assari, ${ }^{145}$ and others ${ }^{146}$ have also shown that religion involvement better promotes health of Blacks than Whites. Lincoln has also shown that social support better protects Blacks than Whites. ${ }^{147}$

\section{Conclusion}

To conclude, equal resources result in unequal health gains for Whites and Blacks in the United States. Policies should not merely focus on equalizing the distribution of resources; policies should also target the differential distribution of barriers across groups.

Ethical issues

Not applicable.

Competing interests

Author declares that he has no competing interests.

Author's contribution

$\mathrm{SA}$ is the single author of the paper.

Funding

Shervin Assari is supported by the Heinz C. Prechter Bipolar Research Fund and the Richard Tam Foundation at the University of Michigan Depression Center, Ann Arbor, MI, USA.

\section{References}

1. Conti G, Heckman J, Urzua S. The education-health gradient. Am Econ Rev. 2010;100(2):234-238. doi:10.1257/aer.100.2.234

2. Everson-Rose SA, Lewis TT. Psychosocial factors and cardiovascular diseases. Annu Rev Public Health. 2005;26:469500 .

3. Mirowsky J, Ross CE. Life course trajectories of perceived control and their relationship to education. Am J Sociol. 2007;112:13391382.

4. Ross CE, Mirowsky J. Explaining the social patterns of depression: control and problem solving--or support and talking? $J$ Health Soc Behav. 1989;30(2):206-219.

5. Bobak M, Pikhart $H$, Hertzman C, Rose R, Marmot $M$. Socioeconomic factors, perceived control and self-reported health in Russia. A cross-sectional survey. Soc Sci Med. 1998;47(2):269-279.

6. Ward MM. Sense of control and self-reported health in a population-based sample of older Americans: assessment of potential confounding by affect, personality, and social support. Int J Behav Med. 2013;20(1):140-147. doi:10.1007/s12529-0119218-x

7. Mirowsky J, Ross CE. Education, Social Status, and Health. New York: Aldine de Gruyter; 2003.

8. Syme SL. Control and health: a personal perspective. In: Steptoe A, Appels A, ed. Stress, Personal Control and Health. London: Wiley; 1989:3-18.

9. Matthews KA, Gallo LC. Psychological perspectives on pathways linking socioeconomic status and physical health. Annu Rev Psychol. 2011;62:501.

10. Zilioli S, Imami L, Slatcher RB. Socioeconomic status, perceived control, diurnal cortisol, and physical symptoms: a moderated mediation model. Psychoneuroendocrinology. 2016;75:36-43. doi:10.1016/j.psyneuen.2016.09.025

11. Phelan JC, Link BG, Tehranifar P. Social conditions as fundamental causes of health inequalities: theory, evidence, and policy implications. J Health Soc Behav 2010;51(suppl):S28S40. doi:10.1177/0022146510383498

12. Link B, Phelan J. Social conditions as fundamental causes of disease. J Health Soc Behav. 1995;36:80-94. doi:10.2307/2626958

13. Farmer MM, Ferraro KF. Are racial disparities in health conditional on socioeconomic status? Soc Sci Med. 2005;60(1):191-204.

14. Bowen ME, González HM. Childhood socioeconomic position and disability in later life: results of the health and retirement study. Am J Public Health. 2010;100(suppl 1):S197-S203. doi:10.2105/AJPH.2009.160986

15. McDonough P, Williams DR, House JS, Duncan GJ. Gender and the socioeconomic gradient in mortality. J Health Soc Behav. 1999 40(1):17-31. doi:10.2307/2676376

16. Marmot MG, Stansfeld S, Patel C, et al. Health inequalities among British civil servants: the Whitehall II study. Lancet. 1991;337(8754):1387-1393.

17. Johnson-Lawrence VD, Griffith DM, Watkins DC. The effects of race, ethnicity and mood/anxiety disorders on the chronic physical health conditions of men from a national sample. Am J Mens Health. 2013;7(4S):58S-67S. doi:10.1177/1557988313484960

18. Stringhini S, Dugravot $A$, Shipley $M$, et al. Health behaviours, socioeconomic status, and mortality: further analyses of the British Whitehall II and the French GAZEL prospective cohorts. PLoS Med. 2011;8(2):e1000419. doi:10.1371/journal. pmed.1000419

19. Leopold L, Engelhardt H. Education and physical health trajectories in old age. Evidence from the Survey of Health, Ageing and Retirement in Europe (SHARE). Int $J$ Public Health. 2013;58(1):23-31. doi:10.1007/s00038-012-0399-0

20. Herd P, Goesling B, House JS. Socioeconomic position and health: the differential effects of education versus income on the onset versus progression of health problems. J Health Soc Behav. 2007;48(3):223-238. doi:10.1177/002214650704800302

21. Gueorguieva R, Sindelar JL, Falba TA, et al. The impact of occupation on self-rated health: cross-sectional and longitudinal evidence from the health and retirement survey. J Gerontol $B$ Psychol Sci Soc Sci. 2009;64(1):118-124. doi:10.1093/geronb/ gbn006

22. Hummer RA, Hernandez EM. The effect of educational attainment on adult mortality in the United States. Population Bulletin. 2013;68(1):1-18.

23. Surtees PG, Wainwright NW, Luben R, Khaw KT, Day NE. Mastery, sense of coherence, and mortality: evidence of independent associations from the EPIC-Norfolk Prospective Cohort Study. Health Psychol. 2006;25(1):102-210.

24. Krause N, Shaw BA. Role-specific feelings of control and mortality. Psychol Aging. 2000;15(4):617-626.

25. Turiano NA, Chapman BP, Agrigoroaei S, Infurna FJ, Lachman M. Perceived control reduces mortality risk at low, not high, education levels. Health Psychol. 2014;33(8):883-890. doi:10.1037/hea0000022

26. Everson-Rose SA, House JS, Mero RP. Depressive symptoms and mortality risk in a national sample: confounding effects of health status. Psychosom Med. 2004;66(6):823-830.

27. Roepke SK, Grant I. Toward a more complete understanding of the effects of personal mastery on cardiometabolic health. Health Psychol. 2011;30(5):615-632. doi:10.1037/a0023480

28. Surtees PG, Wainwright NW, Luben R, Wareham NJ, Bingham SA, Khaw KT. Mastery is associated with cardiovascular disease mortality in men and women at apparently low risk. Health Psychol. 2010;29(4):412-420. 
29. Infurna FJ, Gerstorf D, Ram N, Schupp J, Wagner GG. Longterm antecedents and outcomes of perceived control. Psychol Aging. 2011;26(3):559-575. doi:10.1037/a0022890

30. Gerstorf D, Heckhausen J, Ram N, Infurna FJ, Schupp J, Wagner GG. Perceived personal control buffers terminal decline in well-being. Psychol Aging. 2014;29(3):612-625. doi:10.1037/ a0037227

31. Pudrovska T, Schieman S, Pearlin LI, Nguyen K. The sense of mastery as a mediator and moderator in the association between economic hardship and health in late life. J Aging Health. 2005;17(5):634-660.

32. Assari S, Lankarani MM. Race and Urbanity Alter the Protective Effect of Education but not Income on Mortality. Front Public Health. 2016;4:100. doi:10.3389/fpubh.2016.00100

33. Assari S. Life expectancy gain due to employment status depends on race, gender, education, and their intersections. J Racial Ethnic Health Dispar. 2017. doi:10.1007/s40615-0170381-x

34. Assari S. Perceived neighborhood safety better predicts 25-year mortality risk among Whites than Blacks. J Racial Ethnic Health Dispar. 2016. doi:10.1007/s40615-016-0297-x

35. Assari S, Lankarani MM, Burgard SA. Black White difference in long term predictive power of self-rated health on all-cause mortality in United States. Ann Epidemiol. 2016;26(2):106-114. doi:10.1016/j.annepidem.2015.11.006

36. Assari S, Burgard SA, Zivin K. Long term reciprocal associations between depression and chronic medical conditions; longitudinal support for Black-White health paradox. J Racial Ethnic Health Dispar. 2015;2:589-597. doi:10.1007/s40615-015-0116-9

37. Assari S, Moazen-Zadeh E, Lankarani MM, Micol-Foster V. Race, depressive symptoms, and all-cause mortality in the United States. Front Public Health. 2016;4:40. doi:10.3389/ fpubh.2016.00040

38. Assari S, Lankarani MM. Chronic medical conditions and negative affect; racial variation in reciprocal associations over time. Front Psychiatr. 2016;7:140. doi:10.3389/fpsyt.2016.00140

39. Assari S. Hostility, anger, and cardiovascular mortality among Blacks and Whites. Res Cardiovasc Med. 2016. doi:10.5812/ cardiovascmed.34029

40. Assari S, Sonnega A, Leggett A, Pepin RL. Residual effects of restless sleep over depressive symptoms on chronic medical conditions: race by gender differences. J Racial Ethnic Health Dispar. 2017;4(1):59-69. doi:10.1007/s40615-015-0202-z

41. Assari S. General self-efficacy and mortality in the USA; racial differences. J Racial Ethnic Health Dispar. 2016. doi:10.1007/ s40615-016-0278-0

42. Assari S. Race, sense of control over life, and short-term risk of mortality among older adults in the United States. Arch Med Sci. 2016. doi:10.5114/aoms.2016.59740

43. Assari S, Burgard SA, Black-White differences in the effect of baseline depressive symptoms on deaths due to renal diseases: 25 year follow up of a nationally representative community sample. J Renal Inj Prev. 2015;4(4):127-135.

44. Assari S, Nikahd A, Malekahmadi MR, Lankarani MM, Zamanian $\mathrm{H}$. Race by gender group differences in the protective effects of socioeconomic factors against sustained health problems across five domains. J Racial Ethn Health Disparities. 2016. doi:10.1007/s40615-016-0291-3

45. Assari S. Combined racial and gender differences in the longterm predictive role of education on depressive symptoms and chronic medical conditions. J Racial Ethnic Health Dispar. 2017;4(3):385-396. doi:10.1007/s40615-016-0239-7

46. Assari S. Ethnic and gender differences in additive effects of socio-economics, psychiatric disorders, and subjective religiosity on suicidal ideation among blacks. Int J Prev Med. 2015;6:53.

47. Assari S. Psychosocial correlates of body mass index in the
United States: intersection of race, gender and age. Iran J Psychiatry Behav Sci. 2016;10(2):e3458. doi:10.17795/ ijpbs-3458

48. Assari S, Lankarani MM. Education and alcohol consumption among older Americans; Black-White Differences. Front Public Health. 2016;4:67. doi:10.3389/fpubh.2016.00067

49. Assari S, Lankarani MM. Association between Stressful Life Events and Depression; Intersection of Race and Gender. J Racial Ethnic Health Dispar. 2016;3(2):349-356. doi:10.1007/ s40615-015-0160-5

50. Assari S. Association between obesity and depression among American Blacks: role of ethnicity and gender. J Racial Ethnic Health Dispar. 2014;1:36-44. doi:10.1007/s40615-014-0007-5

51. Assari S, Thomas A, Cadlwell C, Mincey R. Family socioeconomic status at birth and youth obesity at age 15; race and gender differences in a national urban sample. Journal Urban Health. 2017; Forthcoming.

52. Assari S. Socioeconomic status a vulnerability factor among African American youth; a study of discrimination - depression link. Behav Sci. 2017; Forthcoming.

53. Assari S. Family socioeconomic status protects Whites but not Blacks against a decline in self-rated health. Behav Sci. 2017; Forthcoming.

54. Assari S, Lankarani MM. The association between obesity and weight loss intention weaker among Blacks and Men than Whites and women. J Racial Ethn Health Disparities. 2015;2(3):414420. doi:10.1007/s40615-015-0115-x

55. Kessler RC, Mickelson KD, Williams DR. The prevalence, distribution, and mental health correlates of perceived discrimination in the United States. J Health Soc Behav. 1999;40(3):208-230.

56. Geronimus AT, Pearson JA, Linnenbringer E, et al. Raceethnicity, poverty, urban stressors, and telomere length in a detroit community-based sample. J Health Soc Behav. 2015;56(2):199224. doi:10.1177/0022146515582100

57. Ferraro KF, Kelley-Moore JA. Self-rated health and mortality among black and white adults examining the dynamic evaluation thesis. The Journals of Gerontology Series B: Psychological Sciences and Social Sciences. 2001;56(4):S195-S205.

58. Zajacova A, Dowd JB. Reliability of self-rated health in US adults. Am J Epidemiol, 2011;174(8):977-983.

59. Fuller-Rowell TE, Doan SN, Eccles JS. Differential effects of perceived discrimination on the diurnal cortisol rhythm of African Americans and Whites. Psychoneuroendocrinology. 2012;37(1):107-118. doi:10.1016/j.psyneuen.2011.05.011

60. Fuller-Rowell TE, Curtis DS, Doan SN, Coe CL. Racial disparities in the health benefits of educational attainment: a study of inflammatory trajectories among African American and white adults. Psychosom Med. 2015;77(1):33-40. doi:10.1097/ PSY.0000000000000128

61. Miller JE, Korenman S. Poverty and children's nutritional status in the United States. Am J Epidemiol. 1994;140(3):233-243.

62. Allen AJ, Kuczmarski MF, Evans MK, Zonderman AB, Waldstein SR. Race Differences in Diet Quality of Urban Food-Insecure Blacks and Whites Reveals Resiliency in Blacks. J Racial Ethnic Health Dispar. 2016;3(4):706-712.

63. Barnes LL, de Leon CF, Lewis TT, Bienias JL, Wilson RS, Evans DA. Perceived discrimination and mortality in a population-based study of older adults. Am J Public Health. 2008;98(7):1241-1247. doi:10.2105/AJPH.2007.114397

64. Tang M, Stern Y, Marder K, et al. The APOE- 34 allele and the risk of Alzheimer disease among African Americans, whites, and Hispanics. JAMA. 1998;279(10):751-755.

65. Rajan KB, Barnes LL, Wilson RS, Evans DA, Mendes de Leon CF. Racial differences on association of depressive symptoms with combined basic and instrumental activities of daily living. $J$ 
Gerontol A Biol Sci Med Sci. 2014;69(2):215-222. doi:10.1093/ gerona/glt074

66. Everson-Rose SA, Skarupski KA, Barnes LL, Beck T, Evans DA, Mendes de Leon CF. Neighborhood socioeconomic conditions are associated with psychosocial functioning in older black and white adults. Health Place. 2011;17(3):793-800. doi:10.1016/j. healthplace.2011.02.007

67. Koebnick C, Fischer H, Daley MF, et al. Interacting effects of obesity, race, ethnicity and sex on the incidence and control of adult-onset asthma. Allergy Asthma Clin Immunol. 2016;12:50.

68. Kubzansky L, Berkman L, Seeman T. Social conditions and distress in elderly person: Findings from the MacArthur Studies of Successful Aging. J Gerontol B Psychol Sci Soc Sci. 2000;55B(4):P238-P246.

69. Gavin AR, Rue T, Takeuchi D. Racial/ethnic differences in the association between obesity and major depressive disorder: findings from the Comprehensive Psychiatric Epidemiology Surveys. Public Health Rep. 2010;125(5):698-708.

70. Calle EE, Thun MJ, Petrelli JM, Rodriguez C, Heath CW Jr. Body-mass index and mortality in a prospective cohort of U.S. adults. N Engl J Med. 1999;341(15):1097-1105.

71. Stevens J. Obesity and mortality in Africans-Americans. Nutr Rev. 2000;58(11):346-353.

72. Hogue CJ, Buehler JW, Strauss LT, Smith JC. Overview of the National Infant Mortality Surveillance (NIMS) project--design, methods, results. Public Health Rep. 1987;102(2):126-138.

73. Cené CW, Halladay JR, Gizlice Z, et al. Associations between subjective social status and physical and mental health functioning among patients with hypertension. J Health Psychol. 2016;21(11):2624-2635.

74. Ebong IM, Lopez MR, Kanner AM, Wallace DM. The relationship between mood disorder and insomnia depends on race in US veterans with epilepsy. Epilepsy Behav. 2017;70:80-86.

75. Shaw BA, Krause N. Exploring race variations in aging and personal control. J Gerontol B Psychol Sci Soc Sci. 2001;56(2):S119-S124.

76. Plotnick RD, Garfinkel I, McLanahan SS, Ku I. Better child support enforcement: Can it reduce teenage premarital childbearing? J Fam Issues. 2004;25(5):634-657.

77. Gardener H, Wright CB, Cabral D, et al. Mediterranean diet and carotid atherosclerosis in the Northern Manhattan Study. Atherosclerosis. 2014;234(2):303-310. doi:10.1016/j. atherosclerosis.2014.03.011

78. Katzmarzyk PT, Mire E, Bray GA, Greenway FL, Heymsfield SB, Bouchard C. Anthropometric markers of obesity and mortality in white and African American adults: the pennington center longitudinal study. Obesity. 2013;21(5):1070-1075. doi:10.1002/ oby. 20151

79. Anderson KO, Mendoza TR, Valero V, et al. Minority cancer patients and their providers: pain management attitudes and practice. Cancer. 2000;88:1929-1938.

80. Maynard JW, Fang H, Petri M. Low socioeconomic status is associated with cardiovascular risk factors and outcomes in systemic lupus erythematosus. J Rheumatol. 2012;39(4):777783. doi:10.3899/jrheum.110724

81. Samuel LJ, Thorpe RJ Jr, Bower KM, LaVeist TA. Community characteristics are associated with blood pressure levels in a racially integrated community. J Urban Health. 2015;92(3):403414. doi:10.1007/s11524-015-9936-5

82. Malat J, Mayorga-Gallob S, Williams DR. The effects of whiteness on the health of whites in the USA. Soc Sci Med. 2017. doi:10.1016/j.socscimed.2017.06.034

83. Williams DR, Collins C. U.S. socioeconomic and racial differences in health: patterns and explanations. Annu Rev Sociol. 1995;21:349-386.

84. Kessler RC, Neighbors HW. A new perspective on the relationships among race, social class, and psychological distress. J Health Soc Behav. 1986;27:107-115.

85. Mehta N, Preston S. Are major behavioral and sociodemographic risk factors for mortality additive or multiplicative in their effects? Soc Sci Med. 2016;154:93-99. doi:10.1016/j. socscimed.2016.02.009

86. Kaufman JS, Cooper RS, McGee DL. Socioeconomic status and health in blacks and whites: the problem of residual confounding and the resiliency of race. Epidemiology. 1997;8(6):621-628.

87. Brown TH, O'Rand AM, Adkins DE. Race-ethnicity and health trajectories: tests of three hypotheses across multiple groups and health outcomes. J Health Soc Behav. 2012;53(3):359-377. doi:10.1177/0022146512455333

88. Dressler WW. Health in the African-American community: accounting for health inequalities. Med Anthropol Q. 1993;7:325345.

89. Collins SM. The Making of the Black Middle Class. Social Problems. 1983;30(4):369-382.

90. Wilhelm M. Controversy: In America's pastime, says Frank Robinson, White is the color of the game off the field. People. http://people.com/archive/in-americas-national-pastime-saysfrank-robinson-white-is-the-color-of-the-game-off-the-field-vol27-no-17/. Published 1987.

91. Williams DR, Priest N, Anderson NB. Understanding associations among race, socioeconomic status, and health: patterns and prospects. Health Psychol. 2016;35(4):407.

92. James SA. John Henryism and the health of African-Americans. Cult Med Psychiatry. 1994;18(2):163-182.

93. Sellers SL, Neighbors HW. Effects of goal-striving stress on the mental health of Black Americans. J Health Soc Behav. 2008;49(1):92-103.

94. Bennett GG, Merritt MM, Sollers III JJ, et al. Stress, coping, and health outcomes among African-Americans: A review of the John Henryism hypothesis. Psychol Health. 2004;19(3):369-383.

95. Hudson DL, Neighbors HW, Geronimus AT, Jackson JS. Racial discrimination, John Henryism, and depression among African Americans. J Black Psychol. 2016;42(3):221-243.

96. James SA, Strogatz DS, Wing SB, Ramsey DL. Socioeconomic status, John Henryism, and hypertension in blacks and whites. Am J Epidemiol. 1987;126(4):664-673.

97. Duijkers TJ, Drijver M, Kromhout D, James SA. John Henryism and blood pressure in a Dutch population. Psychosom Med. 1988;50:353-359.

98. Mujahid MS, James SA, Kaplan GA, Salonen JT. Socioeconomic position, John Henryism, and incidence of acute myocardial infarction in Finnish men. Soc Sci Med. 2017;173:54-62. doi:10.1016/j.socscimed.2016.11.034

99. Krieger $\mathrm{N}$. Methods for the scientific study of discrimination and health: an ecosocial approach. Am J Public Health. 2012;102(5):936-944. doi:10.2105/AJPH.2011.300544

100. Gee GC, Ford CL. Structural racism and health inequities: old issues, new directions. Du Bois Rev. 2011;8(1):115-132.

101. Williams DR, Mohammed SA. Racism and health I: pathways and scientific evidence. Am Behav Sci. 2013;57(8). doi:10.1177/0002764213487340

102. Agency for Healthcare Research \& Quality: Population Health: Behavioral and Social Science Insights. Understanding the Relationship Between Education and Health; 2015. http://www. ahrq.gov/professionals/education/curriculum-tools/populationhealth/zimmerman.html.

103. Warner DF, Hayward MD. Early-life origins of the race gap in men's mortality. J Health Soc Behav. 2006;47(3):209-226.

104. Colen CG. Addressing racial disparities in health using life course perspectives: toward a constructive criticism. Du Bois Review: Social Science Research on Race. 2011;8(1):79-94. 105. Monnat SM. Race/ethnicity and the socioeconomic status 
gradient in women's cancer screening utilization: a case of diminishing returns? J Health Care Poor Underserved. 2014;25(1):332-356.

106. Huffman ML, Cohen PN. Racial wage inequality: job segregation and devaluation across US labor markets. Am J Sociology. 2004;109(4):902-936

107. Tomaskovic-Devey D. The gender and race composition of jobs and the male/female, white/black pay gaps. Soc Forces. 1993;72(1):45-76.

108. Jencks C, Mayer SE. Residential Segregation, Job Proximity, and Black Job Opportunities. Inner-City Poverty in the United States; 1990:187-222.

109. Bureau of Labor Statistics, U.S. Department of Labor. Occupational employment by race and ethnicity, 2011. https:// www.bls.gov/opub/ted/2012/ted_20121026.htm. Accessed July 22, 2017.

110. Marmot M. The Health Gap: The Challenge of an Unequal World. Bloomsbury Publishing; 2015.

111. The Institute for Women's Policy Research (IWPR). Importance of Social Security by Gender, Race/Ethnicity, and Marital Status. http://www.iwpr.org/publications/pubs/importance-of-socialsecurity-by-gender-race-ethnicity-and-marital-status-2010. Accessed July 2017. Published 2010.

112. Grogger J. Does school quality explain the recent black/white wage trend? J Labor Econ. 1996:231-253.

113. Gee GC, Ford CL. Structural racism and health inequities: old issues, new directions. Du Bois Rev. 2011;8(1):115-132

114. Reskin B. The race discrimination system. Annu Rev Sociol. 2012;38:17-35. doi:10.1146/annurev-soc-071811-145508

115. Williams DR, Mohammed SA. Racism and health II: a needed research agenda for effective interventions. Am Behav Sci. 2013;57(8). doi:10.1177/0002764213487341

116. Geronimus AT, James SA, Destin M, et al. Jedi Public Health: cocreating an identity-safe culture to promote health equity. SSM Popul Health. 2016;2:105-116.

117. Walberg HJ, Tsai SL. Matthew effects in education. Am Educ Res J. 1983;20(3):359-373.

118. Shaywitz BA, Shaywitz SE, Pugh KR, Constable RT. Sex differences in the functional organization of the brain for language. Nature. 1995;373(6515):607.

119. National Center for Health Statistics. Health United States 1993. Hyattsville, MD: USDHHS; 1994.

120. Kochanek KD, Maurer JD, Rosenberg HM. Why did black life expectancy decline from 1984 through 1989 in the United States? Am J Public Health. 1994;84:938-944.

121. Williams DR, Collins C. U.S. socioeconomic and racial differences in health: patterns and explanations. Annu Rev Sociol. 1995;21:349-386.

122. Kitagawa EM, Hauser PM. Differential Mortality in the United States: A Study in Socioeconomic Epidemiology. Cambridge: Harvard University Press; 1973.

123. Feldman JJ, Makuc DM, Kleinman JC, Cornoni-Huntley J. National trends in educational differentials in mortality. $A m \mathrm{~J}$ Epidemiol. 1989;129(9):19-33.

124. Duleep HO. Measuring socioeconomic mortality differentials overtime. Demography. 1989;26:345-351.

125. Pappas G, Queen S, Hadden W, Fisher G. The increasing disparity in mortality between socioeconomic groups in the United States, 1960 and 1986. N Engl J Med. 1993;329:103-115.

126. Wagener DK, Schatzkin A. Temporal trends in the socioeconomic gradient for breast cancer mortality among U.S. women. Am J Public Health. 1994;84:1003-1006.

127. Rowley DL, Hogue CJR, Blackmore AC, et al. Preterm delivery among African-American women: a research strategy. Am $\mathrm{J}$ Prev Med. 1993;9:14.
128. Castro KG. Distribution of acquired immunodeficiency syndrome and other sexually transmitted diseases in racial and ethnic populations, United States: influences of life-style and socioeconomic status. Ann Epidemiol. 1993;3:181-184.

129. Pager $D$, Shepherd $H$. The sociology of discrimination: racial discrimination in employment, housing, credit, and consumer markets. Annu Rev Sociol. 2008;34:181-209.

130. Rabinowitz JL, Sears DO, Sidanius J, Krosnick JA. Why do White Americans oppose race-targeted policies? Clarifying the impact of symbolic racism. Polit Psychol. 2009;30(5):805-828.

131. Williams DR. Miles to go before we sleep: Racial inequities in health. J Health Soc Behav. 2012;53(3):279-295.

132. Ceci SJ, Papierno PB. The rhetoric and reality of gap closing: when the "have-nots" gain but the "haves" gain even more. $A m$ Psychol. 2005;60(2):149-160.

133. Williams DR, Purdie-Vaughns V. Needed interventions to reduce racial/ethnic disparities in health. $J$ Health Polit Policy Law. 2016;41(4):627-651. doi:10.1215/03616878-3620857

134. Lorenc T, Petticrew M, Welch V, Tugwell P. What types of interventions generate inequalities? Evidence from systematic reviews. J Epidemiol Community Health. 2013;67(2):190-193. doi:10.1136/jech-2012-201257

135. Williams DR, Mohammed SA, Leavell J, Collins C. Race, socioeconomic status, and health: complexities, ongoing challenges, and research opportunities. Ann N Y Acad Sci. 2010;1186:69-101. doi:10.1111/j.1749-6632.2009.05339.x

136. Fuller-Rowell TE, Doan SN. The social costs of academic success across ethnic groups. Child Dev. 2010;81(6):16961713. doi:10.1111/j.1467-8624.2010.01504.x

137. Hummer RA, Ellison CG, Rogers RG, Moulton BE, Romero RR. Religious involvement and adult mortality in the United States: review and perspective. South Med J. 2004;97(12):1223-1230.

138. Hummer RA, Rogers RG, Nam CB, Ellison CG. Religious involvement and U.S. adult mortality. Demography. 1999;36(2):273-285.

139. Keyes CL. The Black-White paradox in health: flourishing in the face of social inequality and discrimination. J Pers. 2009;77(6):1677-1706. doi:10.1111/j.1467-6494.2009.00597.x

140. Ryff CD, Keyes CL, Hughes DL. Status inequalities, perceived discrimination, and eudaimonic well-being: do the challenges of minority life hone purpose and growth? J Health Soc Behav. 2003;44(3):275-291.

141. Kessler RC. Stress, social status, and psychological distress. $J$ Health Soc Behav. 1979;20:259-272.

142. Krause N. Assessing supportive social exchanges inside and outside religious institutions: Exploring variations among Whites, Hispanics, and Blacks. Social Indicators Research. 2016;128(1):131-146.

143. Krause N, Ironson G. Positive God images and positive emotions toward God: exploring variations among Whites, Blacks, and Hispanics. Pastoral Psychology. 2017;66(2):269-280.

144. Krause N. Church-based social support and health in old age: exploring variations by race. J Gerontol B Psychol Sci Soc Sci. 2002;57(6):S332-S347.

145. Assari S. Race and ethnicity, religion involvement, church-based social support and subjective health in United States: a case of Moderated Mediation. Int J Prev Med. 2013;4(2):208-217.

146. Reese AM, Thorpe RJ Jr, Bell CN, Bowie JV, LaVeist TA. The effect of religious service attendance on race differences in depression: findings from the EHDIC-SWB study. J Urban Health. 2012;89(3):510-518. doi:10.1007/s11524-011-9659-1

147. Lincoln KD, Chatters LM, Taylor RJ. Psychological distress among Black and White Americans: differential effects of social support, negative interaction and personal control. J Health Soc Behav. 2003;44(3):390-407. 